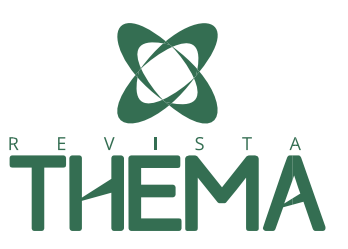

\title{
Aspectos da elaboração de livro paradidático para o ensino de Probabilidade nos anos finais do Ensino Fundamental
}

\author{
Aspects of preparing paradidactic book the teaching of \\ probability in the final years of Elementary Education \\ Ailton Paulo de Oliveira Júnior ${ }^{1}$; Valéria Ciabotti ${ }^{2}$
}

\section{RESUMO}

O objetivo deste trabalho é apresentar o trilhar do processo de elaboração do livro paradidático "Jogando na Olimpíada Nacional de Probabilidade" para subsidiar o ensino de conteúdos probabilísticos dos anos finais do Ensino Fundamental e que atendam às necessidades de compreensão e assimilação por parte dos alunos que estão terminando um ciclo de estudos. Acredita-se ser necessário investigar e buscar uma compreensão mais ampla e fundamentada sobre o uso de livros paradidáticos tanto no desenvolvimento da leitura quanto na escrita e consequentemente nos conteúdos de Probabilidade. As ações utilizadas no livro paradidático foram elaboradas, tomando como base alguns jogos que a nosso ver são importantes para agregar motivação às atividades e também relacionar os conteúdos probabilísticos a serem abordados, ressaltando a importância de o aluno ter contato com a leitura e interpretação de textos.

Palavras-chave: Livro Paradidático; Ensino de Probabilidade; Ensino Fundamental.

\begin{abstract}
The aim of this paper is to present the tread of the preparation of paradidactic book process "Playing in the National Olympics probability" to support the probabilistic teaching content of the final years of elementary school and that meet the understanding and assimilation needs by the students they are completing a course of study. Believed to be necessary to investigate and seek a broader understanding and based on the use of textbooks books in the development of reading and writing and consequently the probability of content. The shares used in paradidactic book have been prepared, based on a few games that we believe are important to add motivation to the activities and also relate the probabilistic content to be addressed, emphasizing the importance of the student have contact with reading and interpreting texts.
\end{abstract}

Keywords; Book paradidactic; Teaching Probability; Elementary School.

\footnotetext{
${ }^{1}$ UFABC - Universidade Federal do ABC, Santo André/SP - Brasil.

2 UFTM - Universidade Federal do Triângulo Mineiro, Uberaba/MG - Brasil.
} 


\section{INTRODUÇÃO}

A Lei de Diretrizes e Bases 9394/96(LDB), Brasil (1996), em seu artigo 32, inciso I, aponta a grande necessidade de trabalhar com leitura, escrita e interpretação de textos na Educação Básica, com o intuito do desenvolvimento da capacidade de aprender, devendo se voltar para a construção de futuros leitores competentes, desenvolvendo um trabalho interdisciplinar, estimulando o aluno a ser sujeito do seu próprio aprendizado.

Fonseca e Cardoso (2005, p. 66) indicam que "nas aulas de matemática, as oportunidades de leitura não são tão frequentes quanto poderiam, pois, os professores tendem a promover muito mais atividades de "produção matemática", entendida como "resolução de exercícios".

Segundo Smole e Diniz (2001), a predominância do silêncio, no sentido de ausência de comunicação, ainda é comum nas aulas de Matemática. O excesso de cálculos mecânicos, a ênfase em procedimentos e a linguagem usada para ensinar Matemática são alguns dos fatores que tornam a comunicação pouco frequente ou quase inexistente.

Para Machado (2011), compreender é apreender o significado de um objeto ou de um acontecimento; é vê-lo em suas relações com outros objetos ou acontecimentos; os significados constituem, pois, feixes de relações que, por sua vez, se entretecem, se articulam em teias, em redes, construídas socialmente e individualmente, e em permanente estado de atualização.

Aspectos da interação discursiva nas aulas de Matemática através de práticas de leitura de textos matemáticos, ou de textos trazidos à cena escolar para ensinar Matemática, ou ainda de textos que demandam a mobilização de conhecimentos matemáticos para a leitura são apresentados por Fonseca e Cardoso (2005).

E partindo da ideia da utilização de textos para a mobilização de conhecimentos matemáticos para a leitura, Dalcin (2002) estudou a utilização de paradidáticos de Matemática, pensando na relação entre a simbologia matemática, as imagens e o texto escrito dentre as diversas abordagens do conteúdo matemático.

Buscando definir os livros paradidáticos, Yasuda e Teixeira (1995), dizem que são as obras produzidas para o mercado escolar sem as características funcionais e de composição do manual didático.

Partindo da discussão de Munakata (1997), o que define os livros paradidáticos é o seu uso como material que complementa (ou mesmo substitui) os livros didáticos, sendo que esta complementação (ou substituição) passa a ser considerada como desejável, na medida em que se imagina que os livros didáticos por si sejam insuficientes ou até mesmo nocivos.

Para Benetti (2008), sob o ponto de vista editorial, o paradidático é definido como um livro comercial, sem compromisso com a formalidade científica, tendo como objetivo trazer informações sobre a ciência de forma descontraída e informal.

Assim, como o objetivo do paradidático é abordar conteúdo probabilístico, Lopes, Coutinho e Almouloud (2010), dizem que no final da década de 1990, os conceitos básicos de Estatística e Probabilidade, antes quase ignorados na Educação Básica, passaram a ser discutidos pela comunidade educacional e acadêmica, tendo sido incorporados oficialmente à estrutura curricular da disciplina de 
Matemática do Ensino Fundamental e Médio com a publicação dos Parâmetros Curriculares Nacionais - PCN.

Nesse contexto, consideramos oportuno elaborarmos um trabalho que forneça subsídios para a implementação de novas práticas pedagógicas, a partir do estudo e discussão de textos alternativos como os paradidáticos de Probabilidade.

Assim, este artigo irá apresentar a trajetória da elaboração de atividades a serem desenvolvidas a partir dos paradidáticos, ou seja, a produção de material que contemple aspectos relacionados aos conteúdos probabilísticos e à leitura, com o intuito de proporcionar aos alunos a vivência dos processos apontados por Nacarato e Lopes (2005), ou seja, que processos como comunicação de ideias, interações, práticas discursivas, representações matemáticas, argumentações e negociação de significados, sejam utilizados.

\section{PROCEDIMENTOS METODOLÓGICOS}

A elaboração do material considera os seguintes aspectos que são realizados concomitantemente:

(1) Criar a estória que será o fio condutor das ações a serem desenvolvidas;

(2) Criar personagens;

(3) Escolher os conteúdos que serão abordados;

(4) Desenhar as ilustrações e gravuras;

(5) Elaborar o texto.

Inicialmente foi escolhido o conteúdo de Probabilidade para os anos finais do Ensino Fundamental como tema principal do paradidático, ao concordarmos com Rezende e Ferreira (2011) ao afirmar que o ensino de Probabilidade na Educação Básica muitas vezes é deixado de lado e, quando ocorre, ainda é feito com recurso da memorização de conteúdos e fórmulas.

Nos PCN, as noções de Probabilidade são propostas desde o Primeiro Ciclo do Ensino Fundamental e tem como finalidade fazer o aluno compreender as diversas situações de acaso e incerteza com as quais se depara em seu cotidiano (BRASIL, 1997).

Definiu-se, portanto, os conteúdos de Probabilidade dos anos finais do Ensino Fundamental como tema principal do paradidático. Assim, os tópicos que foram abordados no livro estão de acordo com o Conteúdo Básico Comum - CBC (2008), Matemática - do $6^{\circ}$ ao $9^{\circ}$ ano do Ensino Fundamental do estado de Minas Gerais, e os Parâmetros Curriculares Nacionais (PCN) Matemática - Terceiro e Quarto Ciclos do Ensino Fundamental, Brasil (1998), sendo estes:

(1) Conceito de Aleatoriedade e Determinístico;

(2) Experimento Aleatório;

(3) Espaço Amostral;

(4) Evento;

(5) Definição de Probabilidade. 
Após a definição do tema pensou-se em como elaborar a estória principal do livro abordando os tópicos citados acima. Teve-se então, a ideia de desenrolar a estória com base em uma Olimpíada de Probabilidade, em que alunos de várias escolas competiriam, passando por várias etapas, sendo elas, inicialmente, na própria escola, seguida da etapa municipal, etapa estadual e finalmente a etapa nacional, onde se declararia o vencedor da olimpíada.

A ideia da criação da Olimpíada de Probabilidade, surgiu a partir do conhecimento da Olimpíada Brasileira de Matemática das Escolas Públicas (OBMEP) que é uma realização do Instituto Nacional de Matemática Pura e Aplicada - IMPA, e tem como objetivo estimular o estudo da matemática. Desta forma, pensou-se que a realização de uma Olimpíada de Probabilidade poderia também estimular o estudo da Probabilidade e motivar os alunos a aprenderem mais sobre este importante conteúdo para sua formação.

Além disso, partimos do princípio de que os jogos podem ser atividades excelentes para a introdução de conceitos do campo da Probabilidade. Segundo Brasil (2010) estes ajudam a compreender a diferença entre situações aleatórias e determinísticas ou a diferenciar possibilidades de probabilidade.

Dessa forma, decidiu-se utilizar atividades com jogos para trabalhar os conteúdos probabilísticos, inserindo-os nas etapas das olimpíadas em que os personagens irão participar para se tornarem campeões nacionais. Os jogos e as respectivas etapas serão descritos na apresentação da elaboração do livro paradidático.

Lopes (1998, p. 40) declara que é "necessário desenvolver uma prática pedagógica na qual sejam propostas situações em que os estudantes realizem atividades, observando e construindo os eventos possíveis, através de experimentação concreta". Recomenda ainda o ensino das noções probabilísticas baseado em uma metodologia heurística e ativa, através da proposição de problemas concretos e da realização de experimentos reais ou simulados.

\section{DEFINIÇÃO DO TEMA}

Para que o conhecimento seja construído é fundamental que se proponha um contexto onde haja um sujeito que vai receber as informações e um sujeito que vai transmiti-las.

Pensando nisso, criaram-se personagens fictícios que assumissem esses papeis como exemplo para os leitores (alunos, principalmente) dos objetivos dentro das salas de aula, e do funcionamento da relação entre os envolvidos nesses momentos de aprendizado. Os nomes foram escolhidos aleatoriamente, seguindo o perfil das figuras criadas por arte finalista que foi contratado para desenhar os personagens a partir das características estabelecidas para cada um deles.

Em se tratando do ambiente escolar, não haveria melhor local para utilizar o paradidático proposto, não querendo inferir que não possa ser lido ou usado em outros lugares. Além disso, aperfeiçoa o objetivo final trazendo a realidade do público leitor alvo para que se familiarizem ainda mais com os temas propostos.

Definiu-se que para a construção deste livro paradidático, a utilização da narrativa ficcional segundo Dalcin (2002), pois se acredita que contar uma estória provocará maior motivação aos alunos em sua leitura e utilização como elemento de fixação e aprendizagem dos conteúdos probabilísticos. 
No estudo de Dalcin (2002) é feita análise de livros paradidáticos no mercado editorial brasileiro sendo identificadas três categorias de abordagem dos conteúdos matemáticos presentes: narrativas ficcionais, narrativas históricas e pragmáticas, cada uma delas apresentando características diferentes na forma de articular a simbologia matemática, as imagens e o texto escrito.

Assim, tendo como público alvo na pesquisa, adolescentes do $9^{\circ}$ ano cuja faixa etária é entre 13 e 15 anos, a opção pela narrativa ficcional na escrita do paradidático foi movida pelo desafio de além de formar leitores na atual evolução tecnológica, despertar o interesse pelo conteúdo de Probabilidade. Acredita-se que para atrair esse público é interessante que a leitura aconteça na forma de trazer prazer e os conteúdos probabilísticos no material vão aparecendo no decorrer da história.

Segundo Mandarino (2010), desde os primeiros anos de escolarização, os alunos podem lidar, em jogos e brincadeiras, com princípios de contagem e estabelecer resultados possíveis, o que, por sua vez, abre caminho para problemas simples e curiosos de probabilidades, ou de "chance" de ocorrência de um resultado.

Após a definição do tipo de história, conteúdos e ciclo a qual se destina, foram selecionados e observados livros didáticos de Matemática para o $9^{\circ}$ ano do Ensino Fundamental, recursos vistos pela cultura escolar brasileira como uma ferramenta, senão a única para orientar o ensino para os professores, referentes aos capítulos que abordassem o ensino de Probabilidade.

Na sequência foram escolhidos oito livros didáticos, todos distribuídos anualmente pelo Ministério da Educação referente ao Programa Nacional do Livro Didático (PNLD) por intermédio do Fundo Nacional de Desenvolvimento da Educação (FNDE) para que se pudesse avaliar de que forma os conteúdos probabilísticos são apresentados. Tomou-se o cuidado na seleção dos anos de publicação, entre 2006 a 2014.

Diante dessa situação nova e complexa questionou-se: como organizar o conteúdo? Qual recurso usar? Como e onde abordar o tema? Como estabelecer relações com outros temas?

Partiu-se então para a procura e leitura de livros paradidáticos de temas variados, inclusive aqueles que abordassem o conteúdo de Probabilidade para o Ensino Fundamental. Encontrou-se no caso do ensino de Probabilidade no mercado editorial brasileiro, livros de ficção de autores estrangeiros, o que indica não haver autor nacional que produza livros paradidáticos para o Ensino de Probabilidade.

Assim, os livros classificados como de ficção, que mesmo sem serem considerados efetivamente paradidáticos, podem ser utilizados como material de apoio ao ensino de Probabilidade são:

(1) "As Novas Aventuras de Sherlock Holmes - Casos de Lógica, Matemática e Probabilidade", Bruce (2003);

(2) "O Segredo da Nuvem", Brandão (2006);

(3) "O Andar do Bêbado", Mlodinow (2009);

(4) "Uma senhora toma chá", Salsburg (2009);

(5) "A Probabilidade Estatística do Amor à Primeira Vista", Smith (2013).

O livro de Bruce (2003), apresenta o mestre dos detetives londrinos Sherlock Holmes e seu fiel escudeiro Watson, revividos pelo físico Colin Bruce autor do livro, em pequenos e divertidos casos 
nos quais criminosos e espertalhões têm seus planos frustrados por meio de seus profundos conhecimentos de probabilidade, estatística e teorias dos jogos. O livro em nossa avaliação é voltado para alunos do Ensino Médio e Superior.

Brandão (2006) apresenta uma história em que o personagem principal vê sua vida cotidiana e monótona desmoronar, porque surge, de uma hora para outra, uma situação absurda e inexplicável, ou seja, uma pequena nuvem apareceu em cima de sua cabeça. A partir desse fato incomum, a sua vida transformou-se em um grande tumulto. O livro é indicado para crianças a partir dos 10 anos.

E Mlodinow (2009) apresenta na visão de um físico, por que as pessoas têm tanta dificuldade em compreender e aceitar o aleatório, apesar de ele controlar uma boa parte de suas vidas.

Segundo Ribeiro (2009, p. 67) o livro de Salsburg (2009) é interessante para o pesquisador que usa a Probabilidade e a Estatística em seu trabalho, sendo uma leitura para quem esteja interessado em conhecer melhor a história das ciências modernas. O historiador da ciência mais especializado, no entanto, talvez sinta falta de explicações mais detalhadas e profundas sobre a história da Probabilidade e da Estatística, mas o livro não se destina ao historiador profissional. O livro em nossa avaliação é voltado para alunos do Ensino Médio e Superior.

Em Smith (2013) é indicado para o público jovem adulto, mas por ser uma história romântica é capaz de conquistar fãs de todas as idades. O fio condutor da história parte da seguinte pergunta: Quem imaginaria que quatro minutos poderiam mudar a vida de alguém? Mas é exatamente o que acontece com Hadley, pois presa no aeroporto em Nova York, esperando outro voo depois de perder o seu, ela conhece Oliver, um britânico em viagem para Londres. Enquanto conversam, eles provam que o tempo é, sim, muito, muito relativo.

No Ensino de Matemática, em se tratando especificamente no ensino do conteúdo de Probabilidade, a precariedade do material didático tido como paradidático foi vista a partir do momento que a procura não nos forneceu esse recurso para leitura no sentido de subsidiar o ensino de conteúdos probabilísticos para ser usado pelos professores e alunos.

Segundo Pinto (2013), o uso dos livros paradidáticos ainda não é frequente nas salas de aula. Este trabalho de criação de material paradidático é de suma importância para os profissionais da educação, futuros professores e para a universidade que terá em seu acervo um material disponível no qual ainda é pouco divulgado e utilizado no meio acadêmico.

A pouca disponibilidade de materiais didáticos direcionados para esse tema suscitou a ideia da elaboração de um livro paradidático, esperando que esse recurso pudesse veicular situações do cotidiano do aluno e que proporcionasse o estabelecimento de relações entre conceitos e procedimentos, dando posteriormente, suporte para uma análise crítica do contexto.

\section{CRIAÇÃO DO AMBIENTE E PERSONAGENS}

Para a escolha dos personagens, tomou-se bastante cautela, pensando em representar vários grupos étnicos que compõem a sociedade, pois segundo Rocha (2006) é indiscutível que os livros devam refletir as contribuições desses grupos para a formação da nação e cultura brasileira. Omitir essas contribuições, ou não as reconhecer na sua totalidade, é uma forma de discriminá-las. 
Assim os personagens principais que compõe a estória são: um branco, um índio, um japonês, um negro e um moreno (pele clara e cabelos escuros). Além disso, um dos personagens seria um cadeirante.

Após a inclusão do personagem índio, definiram-se então os personagens como três meninas e dois meninos, utilizando como critério a pesquisa realizada pela PNAD (Pesquisa Nacional de Amostra por Domicílio), divulgado em 2012 pelo IBGE (Instituto Brasileiro de Geografia e Estatística), Brasil (2012), em que no Brasil tem mais mulheres do que homens, sendo que de uma população de 196,9 milhões de habitantes $51,3 \%$ são mulheres e $48,7 \%$ são homens.

Foram definidos então os seguintes personagens principais: Kauê, Rafael, Kaori, Gabriela, Luíza e a professora Rita, personagens que foram desenhados por arte finalista e que são apresentados na Figura 1.

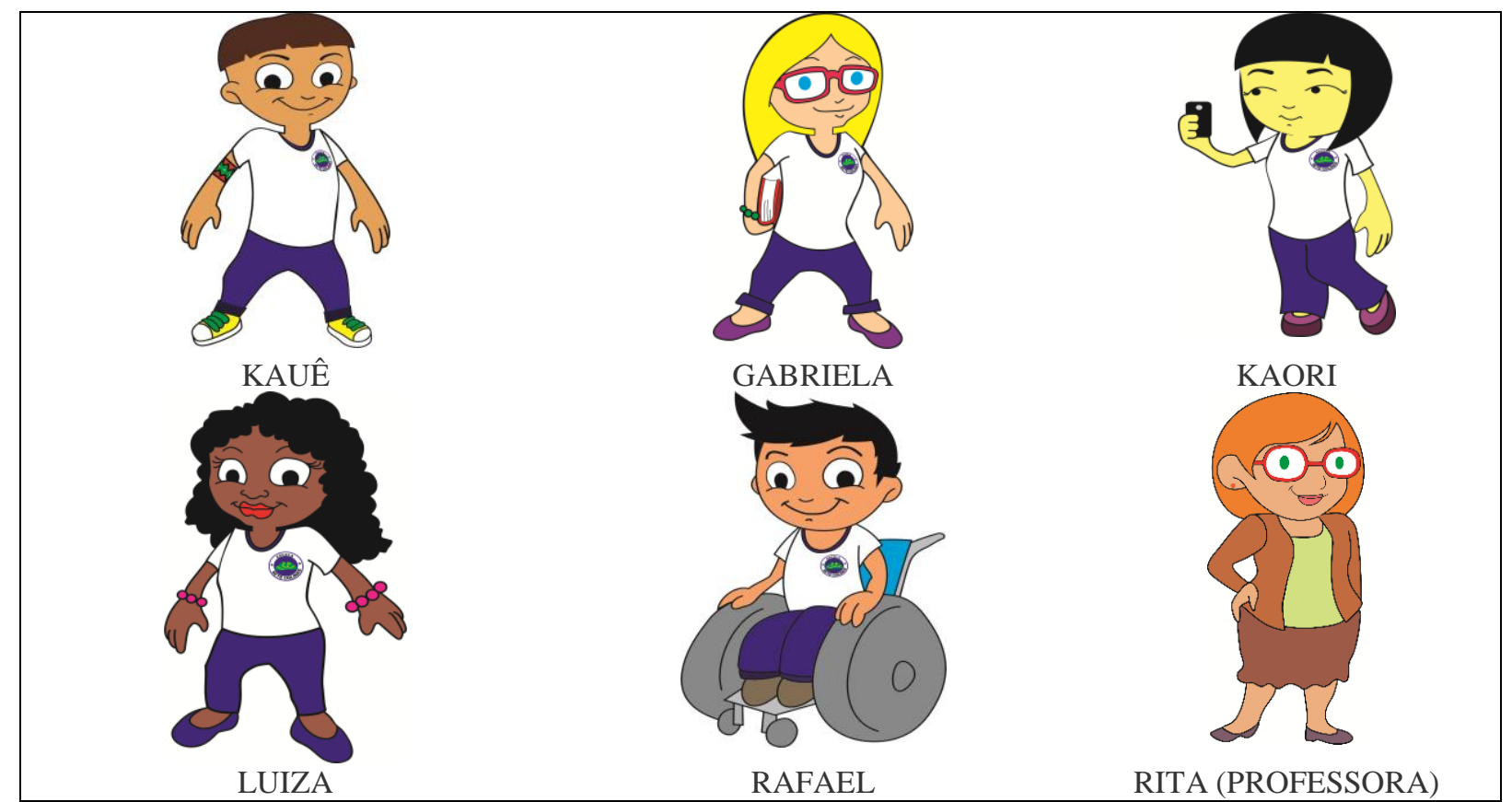

Figura 1 - Imagem dos personagens criados para o livro paradidático.

A escolha do nome "Escola Sete Colinas" pelo grupo, na criação da estória do paradidático, se deu pelo fato dos pesquisadores residirem na cidade de Uberaba-MG e também de homenageá-la, Figura 2.

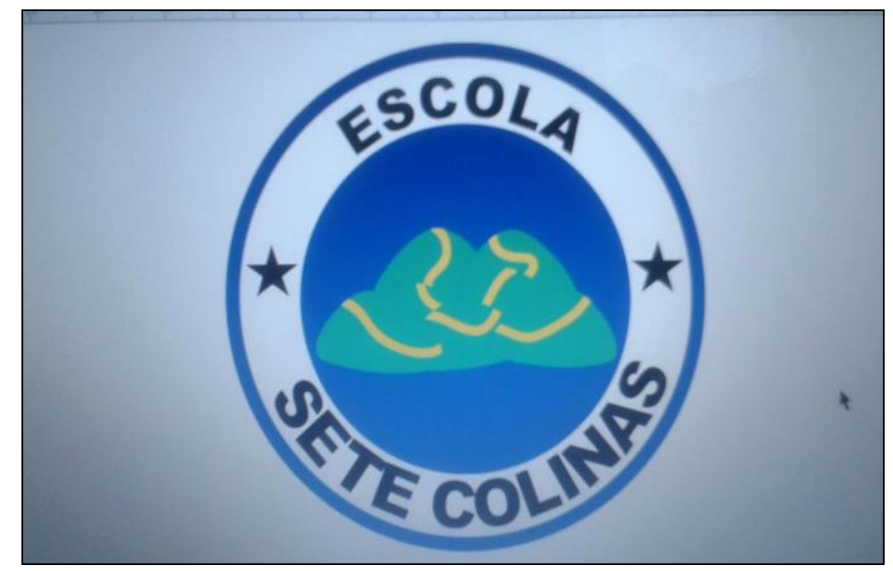

Figura 2 - Logo da Escola Sete Colinas. 
Durante o século XX, Hildebrando Pontes, substituiu o termo Colinas por Altos e identificou mais um Alto, o Fabrício (PONTES, 1978, p. 274). Assim a cidade de Uberaba era referenciada como a Cidade das Sete Colinas.

Em se tratando de ambiente escolar, Figura 3, não haveria melhor local para o desenvolvimento da estória do paradidático que o ambiente de uma escola, não querendo inferir que não possa ser lido ou usado em outros lugares. Além disso, aperfeiçoa o objetivo final trazendo a realidade do público leitor alvo para que se familiarizem ainda mais com os temas propostos.

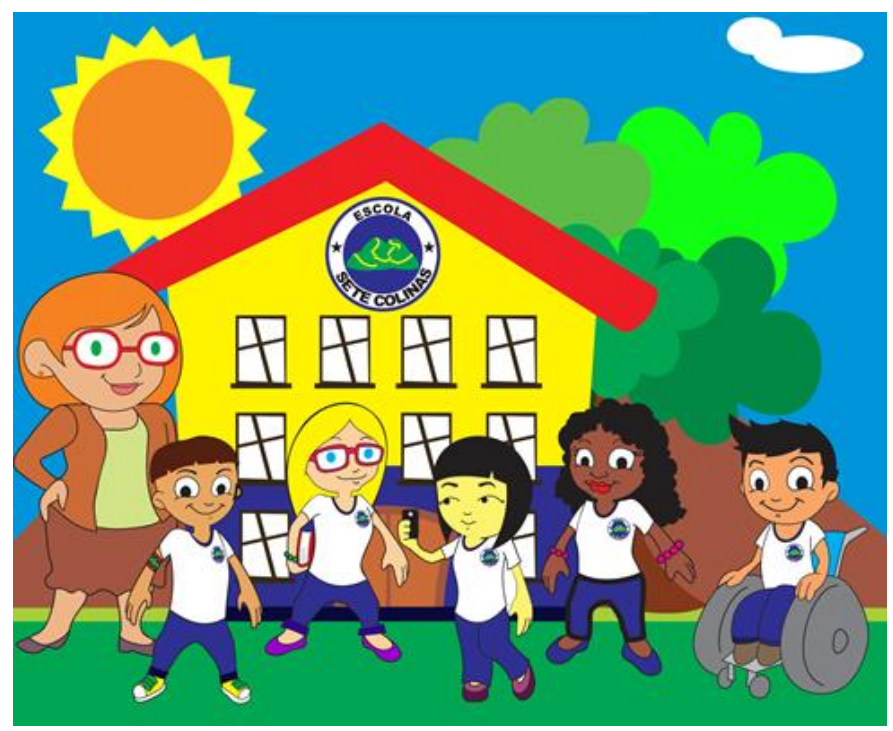

Figura 3 - Ambiente escolar e os personagens.

Segundo Moreira (2007), o ambiente de aprendizagem escolar é um lugar previamente organizado para promover oportunidades de aprendizagem e que se constitui de forma única na medida em que é socialmente construído por alunos e professores a partir das interações que estabelecem entre si e com as demais fontes materiais e simbólicas do ambiente.

Partindo desse pressuposto o ambiente onde se desenvolve a estória do livro paradidático acontece em um ambiente escolar de aprendizagem, tendo o professor um papel importante, tanto na preparação quanto na organização e sistematização desta aprendizagem.

\section{DESCRIÇÃO DOS JOGOS UTILIZADOS EM CADA UMA DAS ETAPAS DA OLIMPÍADA}

Acreditamos que jogos podem ser atividades excelentes para a introdução de conceitos do campo da Probabilidade considerando que auxiliam a compreender a diferença entre situações aleatórias e determinísticas ou a diferenciar possibilidades de probabilidade.

Dessa forma, decidiu-se utilizar jogos para trabalhar os conteúdos probabilísticos, inserindo-os como etapas das Olimpíadas de Probabilidade em que os personagens iriam participar para se tornarem campeões nacionais. O livro paradidático é dividido em capítulos onde em cada um deles será realizada uma das etapas da Olimpíada de Probabilidade.

Esses jogos são aplicados para atuar como ferramenta para a aprendizagem e introduzidos na estória tendo como função a de fixar o conteúdo a ser trabalhado pelo professor. 


\subsection{Primeiro Capítulo: O Jogo do Rapa}

No primeiro capítulo foi abordado o tema da competição enfatizando a informação do acontecimento, cujo nome foi definido como $1^{\text {a }}$ Olimpíada Nacional de Probabilidade (ONP), e esta etapa ocorre dentro das escolas inscritas. Nesse capítulo do livro paradidático é apresentado um folder de divulgação da Olimpíada que acontecerá no decorrer da estória do livro paradidático, Figura 4.

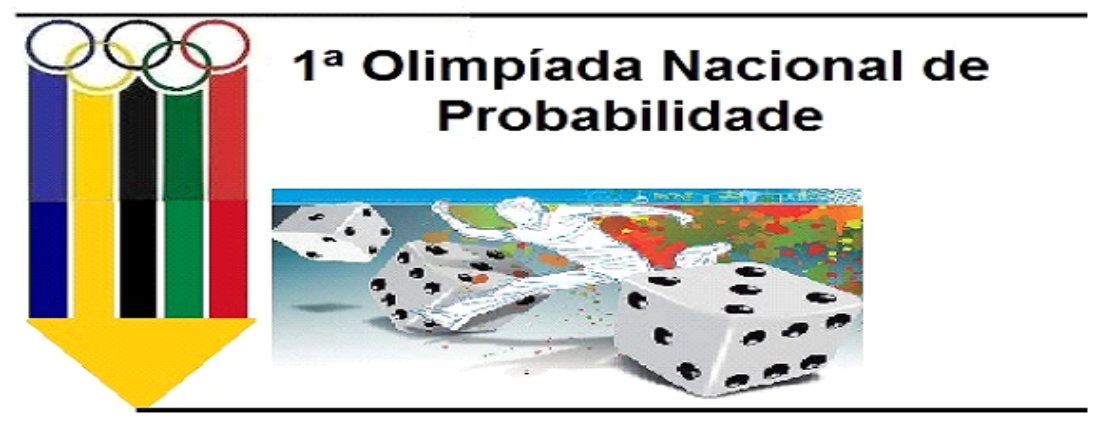

A Olimpíada Nacional de Probabilidade tem como objetivo direcionar e mobilizar alunos e professores para um processo de aprendizagem significativa no ensino de Probabilidade para os alunos do $9^{\circ}$ ano.

A Olimpíada Nacional de Probabilidade será dividida em quatro etapas:

$\checkmark$ A primeira etapa da Olímpiada será realizada nas escolas participantes da seguinte maneira: Em cada turma de $9^{\circ}$ ano será for mado um grupo contendo cinco alunos, esses alunos serão selecionados de forma aleatória, por meio de um sorteio. Depois que todos os grupos da escola forem formados, os mesmos disputarão entre si, obtendo-se então um grupo vencedor entre as turmas de $9^{\circ}$ ano das respectivas escolas, o qual receberá o nome da escola para representá-la durante a Olimpíada Nacional de Probabilidade.

$\checkmark$ Na segunda etapa o grupo ganhador de cada escola irá disputar com os grupos ganhadores das outras escolas do município.

$\checkmark$ Durante a terceira etapa, os grupos ganhadores de cada município do estado disputarão entre si, obtendo-se um grupo vencedor em âmbito estadual, sendo que todos os estados irão participar.

$\checkmark \quad$ E finalmente na quarta e última etapa os grupos vencedores de cada estado disputarão o título de campeão da Olimpíada Nacional de Probabilidade.

Resumindo, será uma disputa em âmbito crescente, ou seja, primeiramente no interior das escolas, posteriormente no município, estado e enfim no País. O grupo vencedor irá ganhar como prêmio um pacote de viagem no valor de $\mathrm{R} \$ \mathbf{5 0 . 0 0 0 , 0 0}$ (Cinquenta mil reais), com destino a escolher, e a escola a qual pertence esse grupo será beneficiada com um laboratório de informática, sendo que em todos os computadores estarão instalados jogos e software que auxiliarão os professores no ensino e aprendizagem de Probabilidade. Os jogos e atividades que serão us ados na competição serão distribuídos para todas as escol as participantes.

Figura 4 - Folder de divulgação da 1a Olimpíada Nacional de Probabilidade (ONP) do livro paradidático.

O jogo que será utilizado no primeiro capítulo é o "Jogo do Rapa" que é um dos mais tradicionais jogos de Portugal e que traz possibilidades em trabalhar conceitos do conteúdo de Probabilidade. Este jogo será utilizado na etapa inicial da Olimpíada, ou seja, etapa que retratará fase da Olimpíada realizada na própria "Escola Sete Colinas".

O objetivo didático é observar que a face virada para cima no lançamento do pião do jogo do Rapa se constitui num modelo probabilístico intuitivo, além do que se deve partir do princípio que o pião do RAPA é feito de material homogêneo e a obtenção de qualquer das letras tem igual probabilidade, indicando eventos equiprováveis. Além disso, pode-se abordar o enfoque clássico de probabilidade.

Considere Dantas (2013, p. 22-23) que adota a seguinte definição de probabilidade:

Consideremos um espaço amostral $\mathrm{S}$ com $\mathrm{N}$ eventos simples, que suporemos igualmente possíveis. Seja $A$ um evento de $S$ composto de $m$ eventos simples. $A$ probabilidade de $A$, que denotaremos por $P(A)$ é definida por: 


$$
P(A)=\frac{m}{N}
$$

Observemos que assim definida, a probabilidade é uma função definida na classe dos eventos ou, o que é equivalente, na classe dos subconjuntos do espaço amostral.

Considere ainda $\mathrm{P}(\mathrm{A})$, a probabilidade de ocorrer o evento $\mathrm{A}$ e o enfoque clássico da probabilidade de ocorrer A sendo dado pela razão: $P(A)=\frac{n(A)}{n(S)}$, onde $\mathrm{n}(\mathrm{A})$ é o número de resultados favoráveis ao evento e $\mathrm{n}(\mathrm{S})$ é o número total de resultados em $\mathrm{S}$.

Para o "Jogo do Rapa" é necessário o uso de um pequeno objeto fabricado em madeira, um pequeno pião, figura 5, composto por quatro faces planas, com um bico em cone e uma ponta superior cilíndrica para ser rodopiada com um movimento de rotação dos dedos polegar e indicador.
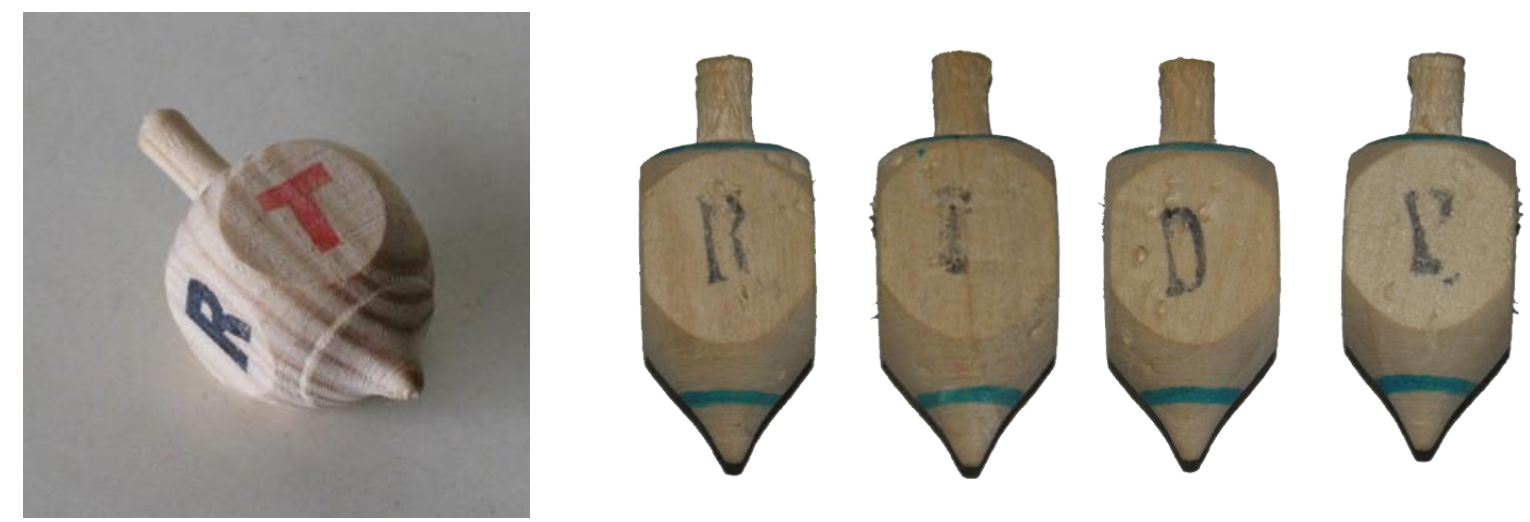

Figura 5 - Pião para o "Jogo do Rapa" e suas faces.

Cabe destacar que pelas dimensões da ponta (onde se produz o movimento inicial de girar) e pino (onde se produz a ação de girar) do pião do Jogo do Rapa, as únicas posições possíveis são as 4 faces planas.

Assim, o RAPA é um jogo tradicional de Portugal em que um cubo tem uma base e um topo como a de um pião para poder rodar livremente até cair e então mostrar uma face para cima.

Cada uma das faces está pintada com uma letra, maiúscula, portanto com um total de quatro letras e que são: $\mathbf{R}, \mathbf{P}, \mathbf{T}, \mathbf{D}$, Figura 5. Assim, cada uma das letras e faces do pião representa o seguinte:

(1) O R significa "Rapa", isto é, o jogador que rodou o pião pode recolher todas as questões ou perguntas que estão no centro do local do jogo. Esta é a jogada mais desejada. O $\mathbf{R}$ permite "rapar" todas as questões ou perguntas em jogo;

(2) O P significa "Põe" onde o jogador deve colocar na mesa questões ou perguntas adicionais;

(3) O D, quer dizer "Deixa", se deve deixar tudo na mesma, sem recolher nem pôr;

(4) Finalmente, o T, significa "Tira", que deve ser retirada questão ou pergunta pelo jogador que rodopiou o pião. Por conseguinte, a jogada mais desejada.

Depois de todos os jogadores terem jogado a sua vez, o jogo é retomado com os jogadores novamente a colocarem cada um uma questão ou pergunta e assim sucessivamente em cada ciclo. 
Desnecessário dizer que se a opção D, "Deixa", se repetir com alguma frequência, o número de questões tende a aumentar pelo que a próxima saída do $\mathbf{R}$, "Rapa", será deveras ambicionada e rentável.

\subsection{Segundo Capítulo: Jogo Mini Bozó}

No segundo capítulo que abordará a Olimpíada em rede municipal de ensino, o jogo a ser utilizado é o Mini Bozó, uma simplificação de um jogo bastante popular no estado do Mato Grosso do Sul conhecido como Bozó, proposto por Lopes (2011).

O jogo Bozó faz parte da cultura local sendo utilizado por Abe (2011) para abordar aspectos da probabilidade e retomado por Lopes (2011) num processo de simplificação do jogo original, sendo criado o Mini Bozó. O jogo Bozó é um jogo que envolve dados e é preciso ter estratégia e sorte. Sorte, pois serão lançados cinco dados simultaneamente e estratégia para fazer a melhor combinação.

O jogo Mini Bozó utiliza dois dados e a mesma estrutura do jogo Bozó e pode ser utilizado nos anos finais do Ensino Fundamental como também no Ensino Médio, e pode subsidiar a prática de professores que ensinam conceitos básicos de Probabilidade.

O capítulo em questão aborda os conteúdos probabilísticos focando ainda os primeiros conceitos de probabilidade nas concepções clássica e frequentista, onde a professora Rita (personagem que faz o papel de professor), explica utilizando material concreto nos experimentos que realiza com os personagens, ou seja, os alunos da estória.

Partindo destas considerações, apresentamos a utilização do enfoque frequentista na elaboração do livro paradidático. Assim, para introduzir este enfoque foi pensando em ser feito a partir da explicação da professora Rita quando da preparação do grupo da Escola Sete Colinas para a Olimpíada Nacional de Probabilidade. Utilizou-se o seguinte exemplo citado no livro paradidático:

Kauê se mostrando muito curioso e com muita vontade de querer provar o que aprendiam, perguntou:

- Professora Rita, surgiu uma dúvida!!! Pensando no lançamento de uma moeda, a probabilidade de sair cara é de 0,5 ou 50\% como já aprendemos, certo? Quer dizer que se lançarmos uma moeda 20 vezes, vai sair cara 10 vezes, pois 20 vezes 0,5 é igual a 10 ?

A professora Rita admirada e muito feliz com a pergunta respondeu:

- Vejo que vocês se interessaram bastante pelo assunto. Kauê, mesmo sabendo que há duas possibilidades no lançamento de uma moeda, não há qualquer garantia de que em 100 lançamentos, 50 serão "cara" e 50 serão "coroa", e que após obtermos uma cara o próximo lançamento será uma coroa. Para mostrar e comprovar isso, vamos realizar esse experimento agora?

- Vou pegar uma moeda na minha bolsa e vamos lançar 100 vezes e depois lançar mais 100 vezes. Vocês vão preencher um quadro como esse que fiz no quadro negro, marcando com um $X$ a face que saiu em cada lançamento e ao final vai somar 0 número de vezes que saiu "Cara" e o número de vezes que saiu "Coroa". 
O objetivo didático é utilizar o jogo para reconhecer o domínio dos alunos em relação a conceitos básicos de Probabilidade (determinação de Espaço Amostral e eventos que o compõe), o que não seria adequado através do jogo Bozó, tendo em vista que este utiliza cinco dados e o Mini Bozó utiliza dois dados.

O tabuleiro do jogo é apresentado na Figura 6.

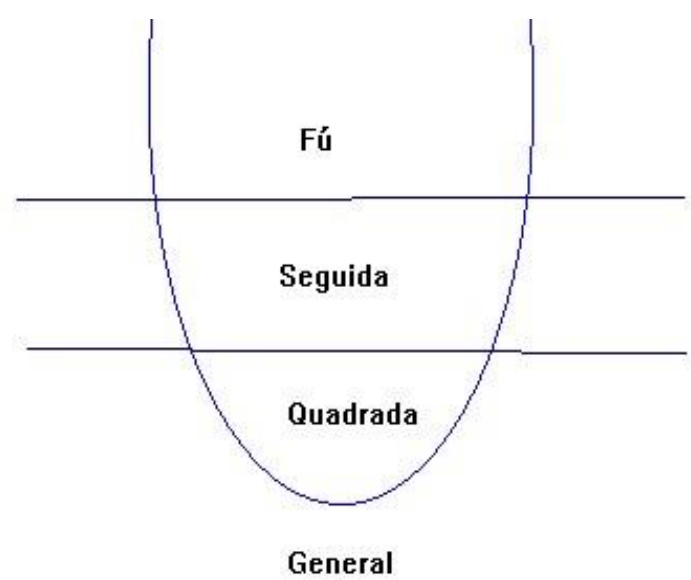

Figura 6 - Tabuleiro do Jogo Mini-Bozó.

O objetivo do jogo é que se preencha todo o tabuleiro, de modo a obter mais pontos que o(s) adversário(s). Além disso, são necessários para que se possa jogar: (1) dois dados; (2) um copo não transparente; (3) papel e caneta para registro dos pontos; e (4) um tabuleiro para cada jogador.

As regras são as seguintes:

(1) Pode ser disputado por duas pessoas ou grupos ou mais, não existindo limite no número de jogadores, mas um número excessivo de jogadores influencia no tempo do jogo;

(2) Em cada jogada, o jogador poderá efetuar até dois lançamentos. O primeiro lançamento é feito sempre com os dois dados. Se o jogador optar pelo segundo lançamento poderá fazê-lo novamente com os dois dados ou reservar um dos dados e efetuar o segundo lançamento com apenas um dado;

(3) Em toda jogada, o jogador deve obrigatoriamente marcar uma casa do seu tabuleiro. Caso não exista possibilidade de marcação ele deve cancelar uma das casas ainda não marcada, fazendo um X sobre a casa que escolheu. Cada casa só pode ser marcada ou cancelada uma única vez;

(4) O jogo termina quando todos os jogadores preencherem suas casas em seus respectivos tabuleiros. Cada jogador soma seus pontos, e ganha àquele que obteve a maior pontuação.

Além das regras, existe uma pontuação para cada atividade desenvolvida, qual seja:

(1) Fú: duas faces distintas, mas não em sequência, vale a soma das faces;

(2) Seguida: duas faces distintas em sequência valem 20 pontos;

(3) Quadrada: duas faces iguais, mas diferentes de 6, vale 30 pontos;

(4) General: duas faces iguais a 6 valem 50 pontos. 


\subsection{Terceiro Capítulo: Jogo Batalha no Trânsito}

No terceiro capítulo onde a competição acontecerá no âmbito estadual definiu-se que o jogo a ser utilizado consiste numa adaptação do jogo "Batalha Naval" a fim de utilizar algo já experimentado pelo público. Nesse capítulo, o conteúdo levará à compreensão pelos alunos dos conceitos de evento; a classificação quanto aos tipos de evento; e espaço amostral. O jogo é chamado "Batalha no Trânsito" baseado no jogo "Batalha Naval".

O objetivo didático é planejar jogadas onde se possa explorar o caráter probabilístico do jogo, tendose a possibilidade de criar situações-problema para práticas pedagógicas de ensino de probabilidade. Esses problemas envolverão a determinação dos seguintes conceitos (FONSECA; MARTINS, 2009):

Espaço Amostral - Para cada experimento aleatório E, define-se Espaço Amostral S o conjunto de todos os possíveis resultados desse experimento.

Eventos - É um conjunto de resultados do experimento. Em termos de conjuntos, é um subconjunto do Espaço Amostral S.

Eventos complementares - O evento complementar de A, denotado $\bar{A}$, é o evento em que A não ocorre. $\bar{A}$ é o evento que ocorre se A não ocorre.

Eventos independentes - Dois eventos são independentes quando a realização ou a não-realização de um dos eventos não afeta a probabilidade de realização do outro evento e vice-versa.

Eventos mutuamente exclusivos - Sejam dois eventos A e B. Se eles não puderem ocorrer simultaneamente, isto é, $\mathrm{A} \cap \mathrm{B}=\varnothing$, então são denominados mutuamente exclusivos;

Probabilidade simples - Razão entre o número de resultados favoráveis ao evento e $\mathrm{n}(\mathrm{S})$, o número total de resultados em $\mathrm{S}$.

Propõe-se com o jogo introduzir aos alunos a partir da elucidação de suas regras, momentos de livre experimentação. Em seguida, após familiarização com o jogo e suas regras, propõe-se aos alunos a análise probabilística das jogadas, introduzindo, gradualmente, conceitos de espaço amostral, ponto amostral, evento e, finalmente, cálculo de probabilidades. Dessa forma, o simples ato de jogar pode levar, com certa naturalidade, ao aprendizado de conceitos e cálculos probabilísticos.

É um jogo de tabuleiro com a participação de dois jogadores e tem como objetivo adivinhar em que quadrados estão as figuras do oponente. O tabuleiro consiste em um quadriculado de 10 por 10 que são enumerados na horizontal com números de 1 a 10 e na vertical letras do alfabeto brasileiro de "A" a "J" onde os jogadores utilizarão figuras simbolizando: bicicletas, motocicletas, carros, ônibus e bitrens (combinação de dois semirreboques acoplados entre si através de uma quinta-roda situada na traseira do primeiro semirreboque, tracionados por um cavalo mecânico), representados na Figura 7, onde no jogo original são representados por tipos de navios. 


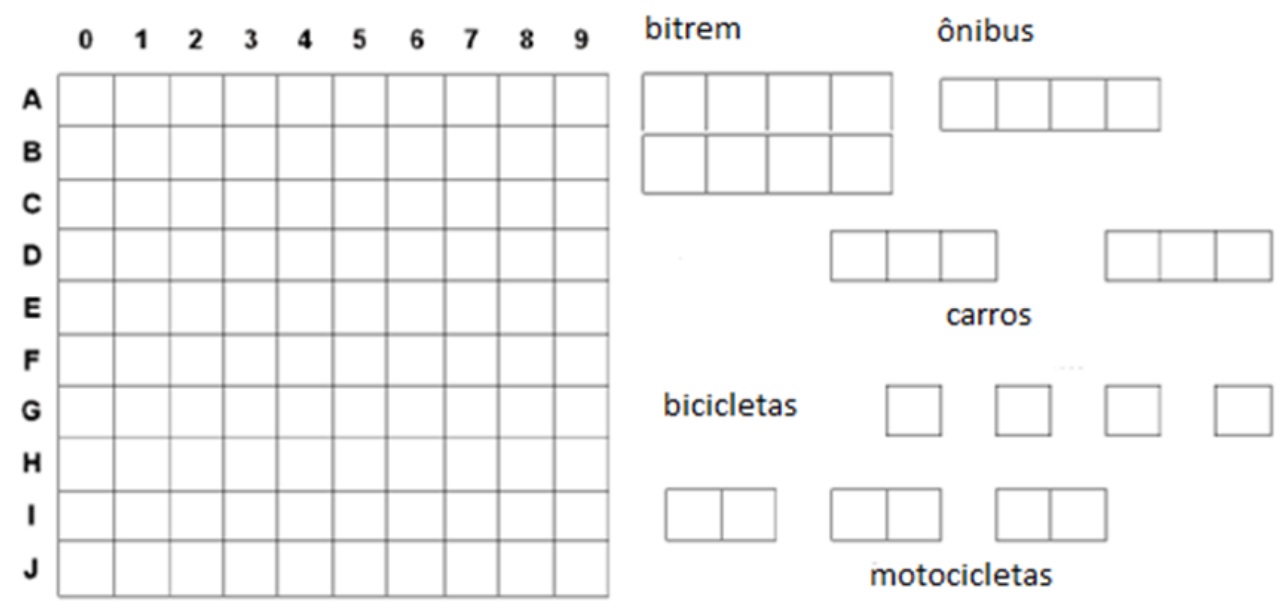

Figura 7 - Tabuleiro e desenhos para o jogo "Batalha no Trânsito".

As figuras que os representam devem ser dispostas aleatoriamente no tabuleiro, horizontal ou verticalmente sem se tocarem nem nos lados e nem nos vértices. O jogador adversário deverá tentar acertar com indicações certeiras dando uma localização das coordenadas representadas por uma letra e um número.

A "Batalha no Trânsito", assim como a "Batalha Naval", é um jogo pensado para dois participantes ou grupo de participantes, onde cada um deverá demonstrar toda sua estratégia e audácia para descobrir e localizar os meios de locomoção terrestres de seu adversário.

\subsection{Quarto Capítulo: Bingo das Probabilidades}

No quarto e último capítulo do livro paradidático, pensou-se na criação de um jogo que abordasse os conteúdos do ensino de Probabilidade para consolidar e fixar substancialmente o objetivo pela qual emergiu a ideia da elaboração de um livro paradidático.

O objetivo didático é utilizar jogos de azar que são aqueles em que a perda ou o ganho dependem mais da sorte do que do cálculo, ou somente da sorte. Estes jogos estão muito ligados às probabilidades. O bingo é um jogo de azar, onde bolas numeradas são colocadas dentro de um globo, e sorteadas uma a uma, até que algum jogador preencha toda a sua cartela com os resultados desse sorteio. Os resultados desses números devem ser marcados em cartelas com números aleatórios. Tradicionalmente, os vencedores são aqueles que conseguirem completar primeiro a cartela e quando acontecer isso os ganhadores devem alertar que ganharam, gritando a palavra "bingo!".

Assim, pensou-se no jogo "Bingo das Probabilidades" criado pelo grupo, onde são fornecidas cartelas aos jogadores representantes de cada grupo, contendo vinte e cinco representações de números ("cinco vezes cinco" relacionados ao número de letras da palavra BINGO). O jogo funciona como um bingo, mas as cartas sorteadas são perguntas sobre Probabilidade sendo que na cartela do jogador apresentam-se valores que o mesmo deverá marcar se for a resposta correta da pergunta sorteada.

Esse jogo compõe a última etapa da Olimpíada que acontecerá a nível nacional em que o grupo formado pelos personagens principais terá que passar para vencer a Olimpíada.

Cabe lembrar que a participação no jogo parte do princípio que o aluno já tenha estudado os conteúdos probabilísticos que farão parte da etapa, ou seja, o paradidático é material didático para a fixação dos conteúdos. 
Na competição, o aluno que representa sua escola, deverá saber a resposta certa e marcar o valor correspondente em sua cartela. Desta forma, definiram-se 9 (nove) perguntas que constam das cartelas fornecidas pelo jogo. São elas:

(1) No lançamento de um dado de 6 faces não viciado, qual a probabilidade de se tirar um número par?

(2) Vinte pedaços de papel são numerados de 1 a 20. Se um desses papéis for sorteado, qual a probabilidade de ser retirado um número entre 5 e 10 ?

(3) No lançamento de um dado não viciado, qual a probabilidade de se tirar um número menor que 5 ?

(4) No lançamento de dois dados não viciados, qual a probabilidade de se obter soma igual a 3?

(5) Formando todos os números possíveis de três algarismos distintos com os dígitos 1, 2 e 3, qual é a probabilidade de, na escolha de um desses números, ele ser maior que 100 ?

(6) No lançamento de dois dados não viciados, qual a probabilidade de se obter soma igual a 1?

(7) Em um estojo, há 6 canetas azuis e 4 vermelhas. Qual a probabilidade de retirarmos desse estojo ao acaso uma caneta azul?

(8) Laura desafiou Denise a resolver uma questão de múltipla escolha com quatro alternativas, em que apenas uma é correta. Porém, Denise não sabe a resposta e vai tentar adivinhar utilizando a sorte. Qual a probabilidade de Denise acertar a questão?

(9) Uma caixa contém 3 bolas azuis, 5 bolas vermelhas e 2 bolas amarelas. Retirando uma delas ao acaso, qual é a probabilidade de não ser bola azul?

Das cartelas distribuídas para os 27 grupos representantes das escolas vencedoras dos Estados do Brasil mais o Distrito Federal, apresenta-se a destinada à Escola "Sete Colinas", Figura 8.

A cartela é constituída por 25 valores aos quais são representações numéricas escritas de diferentes formas tais como: fração, porcentagem, número decimal e na forma inteira, como resultados dos problemas sorteados. Cada cartela contém as respostas corretas, porém expressas de formas diferentes a fim de que o grupo reconheça valores equivalentes para uma mesma solução. Pensando na cartela do jogo do Bingo original, pensamos em 25 valores onde nove são soluções das perguntas que envolvem os conteúdos probabilísticos nessa etapa da Olimpíada.

\begin{tabular}{|c|c|c|c|c|}
\hline B & I & N & G & 0 \\
\hline $50 \%$ & $\frac{3}{10}$ & 1 & $\mathbf{2 / 6}$ & $\frac{1}{100}$ \\
\hline$\frac{1}{9}$ & $\frac{20}{50}$ & 0,7 & $\frac{1}{20}$ & $\mathbf{0 , 1}$ \\
\hline 0 & $\frac{1}{10}$ & $\mathbf{4 0 \%}$ & $\frac{6}{10}$ & $\mathbf{2 0 \%}$ \\
\hline $\mathbf{0 , 6 5}$ & $\frac{2}{3}$ & $\frac{5}{6}$ & $\frac{4}{5}$ & $\mathbf{2 5 \%}$ \\
\hline 0,2 & $\frac{3}{100}$ & $\mathbf{3 0 \%}$ & $\frac{2}{36}$ & $\mathbf{0 , 9}$ \\
\hline
\end{tabular}

Figura 8 - Cartela utilizada no jogo "Bingo das Probabilidades" pela equipe da Escola Sete Colinas.

Assim, os alunos terão que responder às perguntas no local indicado e marcar na cartela as respostas corretas. Após marcarem todas as respostas corretas deverão gritar a palavra "Probabilidade" e assim 
será verificado se realmente a cartela é a vencedora, ajudando assim os personagens que são os alunos da "Escola Sete Colinas" vencer a etapa da Olimpíada.

\section{CONSIDERAÇÕES FINAIS}

A proposta deste trabalho foi mostrar que a elaboração de um livro paradidático pode contribuir para o estudo dos conteúdos probabilísticos de $6^{\circ}$ a $9^{\circ}$ anos, e desta forma incentivar a leitura que desenvolve a habilidade em interpretar textos e também tornar o estudo de probabilidade mais prazeroso.

A intenção da construção do paradidático não é substituir o livro didático e sim complementá-lo e inserir este material como elementos essencial na formação dos alunos da Educação Básica.

É necessário ressaltar também a importância do aluno ter contato com a leitura, escrita, interpretação de textos e até mesmo na comunicação em sua educação inicial, podendo ser auxiliada com o livro paradidático onde ele trabalhará esses três tópicos de uma forma implícita e prazerosa.

Além disso, podemos perceber que esse tipo de livro traz a linguagem matemática e probabilística fazendo com que o educando possa se familiarizar com esse tipo de linguagem e que possa ajudá-lo no uso da mesma em situações cotidianas.

Em termos de conteúdo podemos ressaltar que o paradidático tem maior facilidade de trabalhar a interdisciplinaridade, trabalhando com a relação de diferentes disciplinas e auxilia na parte cultural do educando, fazendo com que o aluno veja sua realidade através dos conhecimentos.

Apresentando a fala de Dalcin (2002), a trazemos como uma das conclusões deste trabalho, ou seja, a utilização de paradidático em Matemática ainda está em processo de maturação e somente se concretizará quando os professores de fato começarem a se tornar autores e/ou coautores, partilhando suas experiências e "pesquisas" em sala de aula.

\section{REFERÊNCIAS}

ABE, Thatiana Sakati. 0 ensino de probabilidades por meio das visões clássica e frequentista. 2011. 192 f. Dissertação (Mestrado em Educação Matemática) - Centro de Ciências Exatas e Tecnologia, UFMS, Campo Grande (MS), 2011.

BENETTI, Márcia. O jornalismo como gênero discursivo. Galáxia, São Paulo, v. 8, n. 15, p. 45-56, 2008.

BRANDÃO, Ignácio de Loyola. O segredo da nuvem. São Paulo: Global, 2006.

BRASIL. Ministério da Educação e Cultura. Lei n. 9.394/96 de 20 de dezembro de 1996. Diretrizes e Bases da Educação. LDB, 1996.

. Secretaria de Educação Fundamental. Parâmetros curriculares nacionais: matemática / Secretaria de Educação Fundamental. Brasília: MEC/SEF, 1997.

- Secretaria de Educação Fundamental. Parâmetros Curriculares Nacionais: Matemática. Brasília: MEC/SEF, 1998. 
2010.

Coleção explorando o Ensino. Brasília: Ministério da Educação, Secretaria de Educação Básica,

Pesquisa Nacional de Amostra por Domicílio - PNAD. Instituto Brasileiro de Geografia e $\begin{array}{lllll}\text { Estatística } & - & \text { IBGE, } & 2012 . & \text { Disponível }\end{array}$ http://www.ibge.gov.br/home/estatistica/populacao/trabalhoerendimento/pnad2012/default_sintese.sht m. Acesso em: 21 jan. 2016.

BRUCE, Colin. Novas Aventuras Científicas de Sherlock Holmes. Rio de Janeiro: Zahar, 2003.

DALCIN, Andréia. Um olhar sobre o paradidático de matemática. 2002, 222f. Dissertação (Mestrado, em Educação Matemática) - Universidade de Campinas - UNICAMP, Campinas, São Paulo, 2002.

2007.

Um olhar sobre o paradidático de matemática. Zetetiké, Campinas, v. 15, n. 27, p. 25-35,

DANTAS, Carlos Alberto Barbosa. Probabilidade: um curso introdutório. 3 ed. rev., 1 reimpressão. São Paulo: Editora Universidade de São Paulo, 2013. (Acadêmica, 10).

FONSECA, Jairo Simon da; MARTINS, Gilberto de Andrade. Curso de estatística. 6. ed. São Paulo: Atlas, 2009.

FONSECA, Maria da Conceição Ferreira Reis; CARDOSO, Cleusa de Abreu. Educação Matemática e letramento: textos para ensinar Matemática, Matemática para ler texto. In: LOPES, Celi Aparecida Eespasandin; NACARATO, Adair Mendes. Escritas e leituras na Educação Matemática. Belo Horizonte: Autentica, 2005. p. 63-76.

LOPES, Celi Aparecida Espasandin. A probabilidade e a estatística no Ensino Fundamental: uma análise curricular. 1998. 133f. Dissertação (Mestrado em Educação) - Faculdade de Educação, Universidade de Campinas, Campinas, 1998.

LOPES, José Marcos. Uma proposta didático-pedagógica para o estudo da concepção clássica de probabilidade. Bolema, Rio Claro (SP), v. 24, n. 39, p. 607-628, ago., 2011.

MACHADO, Nilson José. Matemática e língua materna: análise de uma impregnação mútua. São Paulo: Cortez, 2011.

MANDARINO, Mônica Cerbella Freire. O tratamento da Informação. In: Matemática: Ensino Fundamental/Coordenação João Bosco Pitombeira Fernandes de Carvalho. Coleção Explorando o Ensino da Matemática, vol. 17. Brasília: Ministério da Educação, Secretaria de Educação Básica, 2010.

MINAS GERAIS. Secretaria de Educação. Conteúdo Básico Comum. Belo Horizonte: SEE-MG, 2008.

MLODINOW, Leonard. 0 andar do bêbado - como o acaso determina nossas vidas. Brasil: Zahar, 2009.

MOREIRA, Adelson Fernandes. Ambientes de aprendizagem no ensino de ciência e tecnologia. Belo Horizonte. 2007. In: BRAGANÇA, Bruni; FERREIRA, Leonardo. Augusto Gonçalves; PONTELO; Ivan. Práticas educativas e ambientes de aprendizagens escolar: relato de três experiências. $1^{0}$ Seminário Nacional de Educação Profissional e Tecnológica. Belo Horizonte, 2007.

MUNAKATA, Kazumi. Produzindo livros didáticos e paradidáticos. 1997, 122f. Tese (Doutorado, História e Filosofia da Educação) - Pontifícia Universidade de São Paulo - PUCSP, São Paulo, 1997.

NACARATO, Adair Mendes; LOPES, Celi Aparecida Espasandin. Escritas e leituras na Educação Matemática. Belo Horizonte: Autêntica, 2005. 
PINTO, Anildo Gonçalves. Uma Proposta de Livro Paradidático como Motivação para o Ensino de Matemática. 2013. 73 f. Dissertação (Mestrado em Matemática) - Mestrado Profissional em Matemática em Rede Nacional, Universidade Federal do Rio de Janeiro, Seropédica, 2013.

PONTES, Hildebrando. História de Uberaba e a Civilização do Brasil Central. Uberaba: Academia de Letras do Triângulo Mineiro, 1978.

REZENDE, Fernanda Monteiro de Castro; FERREIRA, Ana Cristina. O Ensino de Probabilidade na Educação Básica: análise da produção de um Grupo de Estudos de professores de Matemática. In: Encontro Brasileiro de Estudantes de Pós-Graduação em Educação Matemática, 15., 2011, Campina Grande (Paraíba). Anais... Universidade Estadual da Paraíba - UEPB, Campus Campina Grande, 2011.

RIBEIRO, Carlos Antônio Costa. A pitoresca história da estatística. Revista Ciência Hoje, Rio de Janeiro, v. 44, n. 264, p. 66-67, out. 2009. Disponível em: <http://www.mat.ufrgs.br/ viali/estatistica/mat2006/material/textos/Resenha_Uma_Senhora.pdf>. Acesso em: 12 set. 2016.

ROCHA, Lauro Cornélio da. As relações étnico-raciais, a cultura afro-brasileira e o projeto político-pedagógico. Salto para o futuro, currículo, relações sociais e cultura afro-brasileira, Boletim 20, Ministério da Educação, 2006.

SALSBURG, David. Uma senhora toma chá...: como a estatística revolucionou a ciência no século XX. Tradução José Maurício Gradel. Rio de Janeiro: Jorge Zahar Ed., 2009.

SMITH, Jennifer E. A Probabilidade Estatística do Amor à Primeira Vista. São Paulo: Galera Record, 2013.

SMOLE, Kátia Stocco; DINIZ, Maria Ignez. Ler, escrever e resolver problemas: habilidades básicas para aprender Matemática. Porto Alegre: Artmed Editora, 2001.

YASUDA, Ana Maria B. G.; TEIXEIRA, Maria. José C. A circulação do paradidático no cotidiano escolar. In: BRANDÃO, Helena Nagamine; MICHELETTI, Guaraciaba. Aprender a ensinar com livros didáticos e paradidáticos. São Paulo: Cortez, 1995. 